\title{
"A-topología" en el Fedro de Platón: el hyperouránios tópos y el filósofo átopos ${ }^{1}$
}

"A-topology" in Phaedrus by Plato: the hyperouránios tópos

and the átopos Philosopher

\author{
María Angélica FIERRO \\ Universidad de Buenos Aires \\ msmariangelica@gmail.com
}

\begin{abstract}
Resumen: Se procura explicar aquí la atopía de Sócrates y del filósofo en general en el Fedro en relación con su emplazamiento en función del hyperouránios tópos como punto de referencia inubicable tanto en un sentido locativo estricto - fuera del universo no había según las concepciones astronómicas de la época nada - como simbólico - remite a un polo de significación que nunca puede despejarse completamente. En tal sentido el filósofo, a través de su búsqueda por la verdad, se encuentra siempre necesariamente "descolocado" respecto del plexo de significaciones tanto dadas como adquiridas.
\end{abstract}

ABSTRACT: Here I intend to explain how Socrates' and the philosopher's atopía in the Phaedrus can be explained as a fundamental "desplacement" of him in relation to the hyperouránios tópos as his fundamental reference point. On one hand, the hyperouránios tópos is nowhere insofar as "outside the universe" there was nothing at all according to the astronomical conceptions of the time. On the other hand, it relates to a an ultimate sense which can never be completely disclosed. Thus the philosopher, through his search for the truth, is always "out of place" regarding not only the discourses of the status quo but also of his own speeches for giving account of reality.

Palabras Clave: a-topía, Fedro, hyperouránios, Platón, Sócrates

KeY wORDS: A-topía, Hyperouránios, Phaedrus, Plato, Socrates

RECIBIDO: 24 de diciembre de 2014 - ACEPTADO: 15 de julio de 2015.

Quien no encaja en el mundo está siempre cerca de encontrarse a sí mismo.

Herman Hesse ${ }^{2}$

El genio de literario de Platón para encarnar su reflexión filosófica en situaciones, individuos concretos y escenarios que cobran vida de inmediato frente al lector de turno alcanza acabada expresión en muchos de

1 Todas las traducciones de los textos griegos son mías y siguen la edición del Thesaurus Linguae Graecae que, a su vez, sigue la de Burnet (1900-1907).

${ }^{2}$ H. Hesse, "Aus einem Brief vom August 1917 an Jakob Flach", citada por Michels 1993 , p. 99. 
sus diálogos. No obstante, el Fedro se destaca por agregar a este diestro entretejido entre ingredientes dramáticos y argumentos filosóficos un cuidadoso trazado topográfico que mantiene de modo sutil la conexión entre el escenario y la conversación a lo largo de toda la obra (Wycherley 1963, p. 90). En efecto, ya desde su frase inagural la obra pone el foco sobre el lugar a donde se encamina $\mathrm{Fedro}^{3} \mathrm{y}$, asimismo, las palabras de cierre ${ }^{4}$ hacen referencia a una toma de distancia respecto del sitio de emplazamiento. También son particularmente notables las correspondencias entre, por una parte, la minuciosa presentación en el prólogo del paseo de Sócrates y Fedro fuera de las murallas de la ciudad, su excursión campestre y su asentamiento a orillas del Iliso para el despliegue de los discursos sobre éros a la vez que del éros por los discursos, y, por otra parte, el relato en el segundo discurso de Sócrates del vuelo de las almas no-humanas desde el ámbito terrestre hacia la planicie de la verdad a través del ouranós, tras la huella, en la medida de sus posibilidades, de la bienaventurada caravana de las almas divinas (Esteban Santos 1992; 1994). La relación entre los tópoi en el Fedro sería, además, compleja, pues, incluso en los casos de evocación de uno a través de otro no tendría lugar una mera repetición, sino que se produce algún tipo de transmutación de su sentido, sumado a que cada tópos estaría vinculado con un tipo determinado de lógos (Philip 1981). Cabe agregar que el preciso mapeo del inicio del diálogo ha sido también productivamente interpretado como un direccionamiento propedeútico del lector para su ingreso y recorrido apropiados del texto (Ferrari 1990).

La inquietud que anima las presentes páginas es la de reflexionar en el marco de este trazado topográfico del Fedro respecto del significado del emplazamiento propio del filósofo, y de Sócrates como su representante, en tanto que se les atribuye en el Fedro un carácter átopos. Uno de los rasgos distintivos del Sócrates de la obra platónica es precisamente el ser átopos, rasgo que Platón hábilmente delinea al establecer un complejo juego con el significado literal del término y sus sentidos más metafóricos. ${ }^{5}$ En efecto, en el rico retrato de su maestro que se desprende de

${ }^{3}$ Phdr., 227a: Ô phíle Phaîdre, poî kaì póthen (Sócrates: “¿Y entonces, Fedro querido? ¿A dónde vas y de dónde vienes?”).

${ }^{4}$ Phdr., 279c: Íomen ("Vamos").

${ }^{5}$ El significado primero y literal del adjetivo á-topos - "lo que no está en su lugar" - así como de su cognado a-topía derivan claramente de sus componentes, esto 
las páginas platónicas éste aparece a menudo como un individuo "atípico" - átopos-, un "des-ubicado" que nunca se encuentra en el lugar esperado, ni en un sentido literal, ni tampoco en un sentido figurado, pues también sus concepciones, conductas e, incluso, apariencia física resultan para la mayoría raros y extravagantes. Si bien la atopía es uno de los rasgos sobresalientes atribuidos al Sócrates del Banquete, sobre todo en el retrato que de él hace Alcibíades, ${ }^{6}$ también es referido de este modo por sí mismo y por otros personajes en otros diálogos platónicos. ${ }^{7}$

es, el prefijo $a$ - - una alfa privativa - , y el sustantivo tópos - "región, lugar" - , y es de aquí que surgen sus otros sentidos derivados, a saber, "extraordinario", "extraño", "paradójico", "raro", "monstruoso", "anormal", "absurdo" e, incluso, "inoportuno". Cf. LSJ s. v. átopos y Chantraine 1968, s. v. tópos.

${ }^{6}$ Camino a la celebración de Agatón, en compañía de Aristodemo, asume una actitud inusitada (átopon, 175a): se detiene a meditar por un tiempo prolongado en un lugar insólito - el pórtico de la casa- (175a) y deja que Aristodemo, quien no estaba invitado, llegue solo (174d-e). También la noción de conocimiento y aprendizaje de Sócrates se sale de las coordenadas habituales: rechaza la idea de Agatón de que la enseñanza sea una especie de inoculación de contenidos (175d-e); se declara ignorante, excepto en cuestiones amorosas (199c-201c). Por ello, pregunta en lugar de responder (199c-201c) y lo que comunica no le pertenece, sino que ha sido relatado por otros que son sabios gracias a un contacto especial con lo divino, (en este caso, la sacerdotisa Diotima, 201d212a). Otros aspectos de conducta también escapan a los parámetros esperables: soporta el frío con impasibilidad; demuestra una valentía incomparable en la batalla; abstemio sin esfuerzo, es al mismo tiempo capaz de ingerir alcohol sin límite y sin embriagarse (219c-221b); íntimo con la alta aristocracia ateniense, él mismo no es rico ni aspira a enriquecerse o a adquirir poder político (216d). Habla, además, con y como la gente del pueblo en el ágora (Rodríguez Adrados 1992), luce, salvo excepciones como este banquete, una indumentaria más bien zaparrastrosa (174a). Asimismo, a pesar de declararse un especialista en cuestiones eróticas y ser un reconocido seductor de jovencitos bellos, rechaza, de modo contrario a la conducta de cualquier erastés del momento, el contacto físico con el más codiciado del momento, Alcibíades (217a-219d). La atopía es justamente el tema de su inolvidable semblanza de Sócrates (cf. 215a y Bury 1909, ad locum). Sumado a todo esto, como trasfondo de la alegría del Banquete y trágico telón de fondo del Fedón (Robin 1951, p. VII), puede mencionarse aquello que selló de modo más indeleble el sentido de su existencia de ahí a la posteridad, esto es, su "extraordinaria" entereza para enfrentar su condena a muerte.

${ }^{7}$ En Alc. I, 106a, el comentario de Alcibíades a Sócrates retoma el tono de sus expresiones del Banquete con su inusual forma de cortejo a lo largo de los años en relación con la de sus otros admiradores. En Grg., 494d así lo califica también Calicles cuando Sócrates le propone el escandaloso ejemplo del hombre que se la pasa rascándose donde le pica como modelo del tipo de placer y felicidad defendido por Calicles. En Tht., 149a Sócrates mismo informa a Teeteto que el común de la gente lo considera atopótatos por conducir en sus conversaciones a los interlocutores a una aporía. No es exclusividad 
Mientras que para algunos intérpretes las referencias a Sócrates como átopos en el Fedro no tendrían ninguna significación especial (vid. De Vries 1969, Phdr., 229c), ${ }^{8}$ otros las han relacionado con "su notable singularidad, la originalidad de su pensamiento y la extravagancia de su comportamiento" (vid. Velardi 2006, Phdr., 229c; mi traducción), esto es con los rasgos idiosincráticos de la semblanza que nos ofrecen de él, como mencionábamos, otros textos platónicos. Por otra parte, hay quienes vinculan la atopía socrática más específicamente, a partir del 230c, con el hecho de que en esta obra en particular Sócrates se encuentra fuera de su escenario natural - la pólis. ${ }^{9}$

Mostraremos aquí, con base en la interpretación de los pasajes relevantes, ${ }^{10}$ que en el caso del Fedro el carácter átopos de Sócrates adopta un sentido particular: la "desubicación" propia del filósofo, consistente en un direccionamiento existencial hacia un sentido último que, cualquiera sea el nivel de recorrido que un alma humana haya alcanzado en el conocimiento de la verdad, deja siempre, incluso a quien haya po-

de Platón relacionar la atopía con Sócrates: también según Jenofonte (Mem., 2, 3, 15), Querécrates califica de átopa los dichos de Sócrates cuando éste le aconseja tomar la iniciativa, a pesar de ser el más joven, de de hacerse amigo de con su hermano Querofón, un consejo menos sorprendente, sin duda, que el retrato que nos brindan los textos platónicos. Asimismo, si bien en Nubes Aristófanes no emplea este término para referirse a Sócrates, su elección de él como personaje a la vez cómico y representativo de los sofistas para el común de la gente se debe sin duda a que era conocido por ser rara avis. Por otra parte, Platón no aplica este calificativo exclusivamente a Sócrates: en $R$., 493 c se describe en estos términos al educador sofista que trata a su audiencia como una bestia y la maneja a través de los discursos que le proporciona placer. En griego ya se empleaba este término para referirse a la conducta absurda de una persona tal como puede verse en Isoc., Panath., 149.

${ }^{8}$ Vid. De Vries 1968, ad locum.

${ }^{9}$ Vid. Rowe 1999.

${ }^{10}$ Los adjetivos átopos y el superlativo atopótatos son empleados en referencia a Sócrates en 229c y 230c respectivamente, y atopía en 251d en relación con el filósofo que rememora lo bello en sí. También en 229e las criaturas híbridas de la tradición mítica que los intelectuales de la época intentan traducir en explicaciones racionales son referidas como "seres extraordinarios" (atopíai). Este último caso no sería directamente relevante para nuestro análisis. Sin embargo, debe considerarse que antecede inmediatamente a la reflexión de Sócrates de la necesidad de cumplir con el mandato délfico del autoexamen para descubir si él es una bestia simple y doméstica, o compleja y furiosa como el personaje mítico de Tifón. Se sugiere, entonces, que lo que ha de determinar es justamente si él mismo no es acaso similar a una de estas atopíai (vid. Brisson 1989, p. 195, n. 38). 
dido cumplimentarla de modo más acabado, "descolocado" o "desubicado", no sólo respecto al plexo de significaciones recibido de su entorno cultural, sino también en relación con los revisados y establecidos a través de su propia búsqueda. ${ }^{11}$ Esto se vincula con interpretaciones recientes respecto de la "singularidad" o atopía socrática en general que la entienden como la ubicación de Sócrates en un "no-lugar" en el sentido de que Sócrates con su práctica filosófica se sitúa en el universo simbólico de su tiempo y al mismo tiempo se desplazaría de él. ${ }^{12}$ No obstante, nuestra interpretación es que, en el caso del Fedro, esto se da de modo más extremo, pues entendemos que aquí la atopía de Sócrates y el filósofo sugiere en último término su desplazamiento y desubicación no sólo respecto del status quo, sino incluso del marco simbólico producido a través del propio examen e investigación en referencia al polo de significados plenos representado por el plano eidético. Esto significa también que, si bien el efecto de "extrañeza" lo transmite Sócrates a través de su distanciamiento de las prácticas políticas de la pólis y de su empleo de los expedientes de la retórica tradicional, esto no se resuelve finalmente "en un orden platónico familiar" que hace que el diálogo "no sea después de todo tan extraño". Por el contrario, el filósofo queda emplazado en un lugar átopos, que nunca termina de franquear, sin lograr instalarse definitivamente en la estabilidad confortable del mundo eidético. Este "no-lugar" es, no obstante, radicalmente distinto al concepto homónimo de la antropología contemporánea: lejos de tratarse de una esfera transitoria y evanescente que no aporta ningún elemento vital para la constitución de la identidad del sujeto, ${ }^{13}$ la atopía del filósofo platónico implica, por el contrario, su emplazamiento en función a un plexo de significaciones que, de desplegarse por completo, le permitirían comprender acabadamente el sentido de su existencia. Es esta ubicación "extraña” la

${ }^{11}$ Una original explicación que se ha ofrecido recientemente de la "singularidad" o atopía socrática en los diálogos tempranos ha sido la de Nudler (2012), quien la entiende como la ubicación de Sócrates, a través de su práctica filosófica, en un lugar límite dentro del orden simbólico del status quo y, en tal sentido, como "no-lugar", puesto que Sócrates se ubica así en el universo simbólico de su tiempo y al mismo tiempo se desplaza de él.

12 Vid. Nudler 2012.

13 Nos referimos a la noción de Augé (1996) de "no-lugar" en tanto espacio del anonimato, tales como las autopistas, aeropuertos, supermercados, relacionada con su concepto de "sobremodernidad". 
que le permite descubrirse, en términos del Banquete, como metaxý, es decir como no sólo situado en un lugar "intermedio" entre lo mortal y lo inmortal sino, además, con la capacidad de funcionar como un "intermediario" entre ambos ámbitos y de volverse, a través del contacto con lo divino, divino él mismo en la medida de lo humanamente posible. ${ }^{14}$

Analizaremos para ello, en primer lugar, cómo ya el prólogo del $\mathrm{Fe}$ dro plantea respecto de Sócrates, en la traslación que realiza desde su propio lugar común de accionar - la pólis - hacia el ámbito rural, un desajuste con respecto al lugar físico y, a la vez, mental que le son habituales. Esta experiencia de un desplazamiento respecto de su perspectiva familiar se incrementa en su reacción maravillada ante el paraje de extraordinaria belleza sensible en el que los personajes se instalan (230b-c) y que inspira en Sócrates, quien ya se ha descrito a sí mismo como alguien "atípico" o "raro" (átopos, 229d), un parlamento por el cual Fedro lo califica justamente como un individuo "rarísimo", "de lo más atípico" (atopótatos, 230c).

En segundo lugar, veremos cómo este mismo sentido de la atopía es retomado y desarrollado en el mito del carro con corceles alados del segundo discurso de Sócrates al describirse allí un desplazamiento de todas las almas hacia un lugar inédito en sus características: el hyperouránios tópos (250c), el cual, desde el punto de vista físico-cosmológico, es un sitio inexistente y al cual, por otra parte, las almas no-divinas, incluidas las filosóficas, tienen a lo sumo un acceso "parcial" o "esforzado" (mógis, 248a). Esto sugeriría que en el Fedro el recorrido de un alma humana en su forma de vida actual y también post mortem - cuyas características están íntimamente ligadas, de acuerdo al mito, a nuestro progreso o retroceso psicológico y cognoscitivo - apuntaría como meta última a una suerte de punto inubicable en coordenadas espaciales reconocibles y que es además, en el mejor de los casos, "apenas" (mógis) franqueable. Esta orientación vital hacia un "no-lugar" implicaría, pues, para el filósofo y el verdadero amante, ejemplicado por Sócrates, una existencia en incómodo desfasaje o atopía (251e), en un desalojo no sólo con respecto a los códigos usuales de su entorno sino también con precario cobijo en el universo de sentidos que él mismo haya logrado construir.

${ }^{14}$ Vid. Fierro 2007. 


\section{De la ciudad al campo: Sócrates átopos y el locus amoenus}

La introducción del Fedro, a través de referencias topográficas ${ }^{15}$ claramente reconocibles, especialmente para el lector de la época naturalmente familiarizado con su hábitat, traza con minucia el itinerario de Sócrates y Fedro. Asimismo se ofrecen indicaciones precisas para imaginar el paisaje, la ubicación temporal e incluso, a través del diálogo vivaz puesto en boca de los personajes, sus tonos, actitudes, estados de ánimo características psicológicas y hasta movimientos corporales. Extrapolando pautas de representación propias de nuestra cultura actual, podría decirse, pues, que el texto funcionaría como una suerte de guión cinematográfico. El carácter realista de la topografía del diálogo, en tanto refiere con toda probabilidad al panorama que efectivamente se desplegaba extramuros (vid. Wycherley 1963), no es incompatible con que tenga también, como veremos, un valor simbólico. ${ }^{16}$

La descripción iniciaría cerca del mediodía (227b), durante el caluroso verano mediterráneo $(229 a ; 230 a ; 259 a)$, con una toma de Sócrates tropezando con Fedro y Sócrates en las proximidades de la casa de Mórico frente al Olympeion o templo de Zeus (227a) y, por lo tanto, si bien esto los situaría en los linderos de la ciudad, se hallarían todavía dentro de ella. A continuación los personajes deciden seguir caminando y conversando (227b), y abandonan así el ámbito urbano para ingresar a un área campestre, de acuerdo con los designios de Fedro, previos al

15 En la reconstrucción de la topografía del Fedro los dos autores fundamentales han sido Robin (1954, pp. X-XII) y Wycherley (1963). Este último tiene en cuenta los hallazgos arqueológicos de Travlos que luego condensaría en su obra de 1971. Velardi (2006, pp. 8-12) sigue fundamentalmente a Wycherley, así como Yunis (2011, pp. 8892) y Ryan (2012, pp. 96-98), quien resume muy bien los principales puntos de la discusión. Todos ofrecen un plano probable para el emplazamiento de los distintos puntos geográficos.

${ }^{16}$ Dusanic (1992, p. 24, n. 12) reconoce sólo su índole simbólica, puesto que para él, a través del trazado del locus amoenus del Fedro, estarían representadas las rivalidades de los distintos grupos políticos de la Atenas de la época. Así la placidez y benevolencia de las deidades de la naturaleza referirían a los ciudadanos atenienses que, como Platón y sus aliados, se oponían a las ambiciones expansionistas de los demócratas radicales simbolizadas a través del mito de Bóreas y Oritia, donde la fuerza de la naturaleza es violenta y destructiva. Ha de tenerse en cuenta que para el momento de composición del Fedro - esto es, entre el 380-360 a. C. (vid. Velardi 2006, p. 62) - ya había concluido la Guerra del Peloponeso que había evidenciado las desastrosas consecuencias de las ambiciones imperialistas de Atenas. 
encuentro, de realizar vigorosas caminatas a campo abierto (227a). La marca divisoria entre una y otra esfera la establecen las murallas que rodeaban a Atenas ${ }^{17}$ y que contaban en su perímetro con unas quince puertas de salida. Sócrates y Fedro emergen quizá por la puerta Diomeia, situada al este, o la puerta Itonia, emplazada al sur, - ambas en las cercanías del templo de Zeus,$-{ }^{18} \mathrm{o}$, más probablemente, por la puerta Hippades, ${ }^{19}$ situada más precisamente al norte del Olympeion; cualquiera de ellas conducentes de todos modos a las proximidades del río Iliso que corría al sur de la ciudad. Al alcanzar el área fluvial los personajes se desvían de la ruta principal, ${ }^{20}$ que era probablemente la que tenía en su planes Fedro, para seguir la corriente de agua ${ }^{21}$ (229a), encontrándose ubicados en ese momento a trescientos o, más bien, ${ }^{22}$ según corrige Sócrates, quinientos metros - esto es, a dos o, más exactamente, tres estadios (229c) - de los peñascos desde donde, según la tradición, el viento Bóreas precipitó y desnucó a Oritía, mientras jugaba con las ninfas, y a la altura del vado por donde habitualmente se cruza $^{23}$ hacia el

${ }^{17}$ Se trata de las murallas que, bajo el consejo de Temístocles, construyó rápidamente Atenas después de la victoria helénica en las guerras persas con el propósito de consolidar su hegemonía sobre los espartanos y el resto de las ciudades griegas. Además de fortificar la ciudad propiamente dicha, Temístocles impulsó también, a fin de mejor garantizar el dominio marítimo ateniense, la construcción de las "grandes murallas" que conectaban a Atenas con sus dos principales puertos: el más antiguo, el Falero, y el más nuevo, el Pireo.

${ }^{18}$ Vid. Robin 1964, pp. X-XII.

${ }^{19}$ Vid. Velardi 2006, pp. 8-12.

${ }^{20}$ De cada puerta de la ciudad se originaba en general una ruta. Así, por ejemplo, de la de Puerta de Hipades — también llamada Aigeus siguiendo a Plutarco (Thes., 12, 6) - salía la ruta a Agrylo, de la puerta Diomeia una al gimnasio Kynosarges y de la puerta Itonia otra al baño de Isthmonikos.

${ }^{21} \mathrm{El}$ adverbio kátothen en 229c significaría entonces que se van desplazando desde donde están "hacia abajo", "por el arroyo" (katà tò hydátion), es decir a lo largo del Iliso, río abajo (229a). Cf. Robin (1954, p. xii, n. 2), De Vries (1969), Yunis (2011) y Ryan (2012, ad locum). Como hace notar Wycherley (1963, pp. 93-94) katá en referencia a ríos siempre implica ir "río abajo" y cita como ejemplo Hdt., 1, 194.

22 El significado de la disyunción è en è tría stádia en 229c sería "o más bien tres estadios". Cf. De Vries 1969.

${ }^{23}$ Seguimos la lectura de Ryan (2012, ad locum) del presente de indicativo diabaínomen, esto es "donde habitualmente cruzamos [los atenienses]". Vid. también Robin 1954, p. XII, n. 2, y De Vries 1969, ad locum. 
templo de $\operatorname{Agra}^{24}$ (229c). Lo más plausible es, pues, que han emergido por la puerta Hippades o por la Diomeia, ya que ello justifica mejor una distancia de recorrido de alrededor de quinientos metros hasta los alrededores del templo de Agra - la puerta Itonia estaría, en cambio, bastante más próxima a éste. Tras ir chapoteando a lo largo de la ribera (229b), finalmente los dos amigos, se detienen probablemente sobre la margen sudeste del río, ${ }^{25}$ para recostarse junto a un alto y frondoso plátano (230a-b; cf. 229a), en un paraje próximo al templo de Agras y de un santuario a Bóreas (229c), y no muy lejos de otro dedicado a divinidades fluviales, tales como las ninfas y Aqueloo. ${ }^{26}$

Una de las funciones del prólogo del Fedro es, pues, la traslación imaginaria del lector, junto con Fedro y Sócrates, en el espacio físico desde un lugar bastante preciso dentro de la ciudad a un recorrido, también

${ }^{24}$ En 229c, los mss. traen tò tês ágras/agraías y el escoliasta tò en Ágras que es la lectura que prefieren, entre otros, Burnet (1905-1908), De Vries (1969) y recientemente Yunis (2011) y Ryan (2012). Se trataría en todo caso de un templo en el demo de Agras situado al sudeste de Atenas, justamente en los alrededores del Iliso. Ierón - "templo" - estaría elidido y habría un uso arcaico del genitivo con valor locativo que acompañaría aquí a en en lugar del dativo e íntimamente conectado con el uso de esta expresión en relación con los misterios según indican diversas inscripciones (vid. Yunis 2011, ad locum). Mientras que el escoliasta sugiere en su lema que se trata de un templo de Artemis, según lo que se sabe de la topografía del lugar habría que suponer más bien que es el templo a Deméter mencionado por J. Stuart \& N. Revett en The Antiquities of Athens (1761) y que fue aniquilado tras el bombardeo turco en la zona. Vid. Robin 1954, p. XII, n. 1.

${ }^{25} \mathrm{La}$ amenaza posterior de Sócrates de cruzar el río y marcharse (242a-b) sugiere que, después de ir caminando remojándose los pies en el vado, Fedro y él se habían ubicado de ese lado. Si estuviera sobre la margen noroeste del río Sócrates tendría que cruzar para irse a campo traviesa hacia el monte Himeto. Vid. Ryan 2012, 229c.

${ }^{26}$ Las imágenes votivas a las que aquí se hace referencia podrían ser las de un bajorrelieve conservado en el Museo Estatal de Berlín donde aparecen Aqueloo, las Ninfas y Pan con sus padres Hermes y Deméter, es decir divinidades relacionadas con los cultos de Eleusis. También el templo de Agra refiere a los Misterios Menores eleusinos, que precedían como ceremonia purificatoria a los Grandes Misterios (vid. nn. 48-49 y 60 infra sobre el simbolismo de los misterios en el Fedro). Por otra parte, según el testimonio de Pausanias $(1,19)$ en las inmediaciones del Iliso habría habido en época de Platón monumentos vinculados a cultos muy antiguos, tales como un santuario a Apolo Pitio - patrono de la mántica inspirada - , un altar dedicado a las Musas Ilisias y otro de Afrodita "en los jardines". Sobre estos detalles vid. Velardi 2006, pp. 10-11. Vemos entonces que el ambiente en el que Fedro y Sócrates son ubicados imaginariamente por Platón está de por sí impregnado de divinidades o por intermediarios de los dioses como es el caso de las Musas (cf. 237a, 259b-d, 262c, 278b, 279c). 
bastante preciso, fuera de ella. Veamos ahora en qué sentido el posicionamiento de Sócrates respecto a este trazado espacial es considerado en el texto como átopos o "fuera de lugar".

En primer lugar cabe observar que la manera en que desde el inicio se presenta a cada uno de los personajes en relación con el espacio sugiere que, mientras que en el caso de Fedro su relación con el territorio es bastante definida, la situación topográfica de Sócrates, en cambio, queda más bien indeterminada. Fedro se propone tomar un camino para él bien conocido, que arranca en la casa de Mórico, detrás del Olympeion, y sigue por una carretera o sendero en las afueras de la ciudad. Tiene, digamos, una respuesta precisa de dónde viene y a dónde va, pregunta inicial que le dirige Sócrates (vid. supra n. 3); está familiarizado con las zonas aledañas de su paseo y no ve en el paisaje que se le propone nada inusual. El objetivo de lo que proyecta lograr en ese trayecto también está fijado de antemano: aprenderse de memoria el discurso retórico de Lisias (228b-c) y, a la vez, tonificarse físicamente según los consejos médicos de Acumeno (227a). En cambio, respecto de Sócrates, no sabemos de dónde viene, tampoco a dónde se dirigía antes de su encuentro con Fedro; se desconcoce también qué propósito tenía su paseo; el encuentro con él produce, además, un desvío en relación con el itinerario que Fedro se había previamente trazado, ${ }^{27}$ se presenta asimismo ante él como desconocedor del área, ${ }^{28}$ (si bien, como veremos luego, nos da indicios de conocerla mejor que el Mirrino); aparentemente habría salido a caminar como Fedro pero, sin embargo, propone detener en un punto la marcha para instalarse en un lugar apropiado para conversar. La razón de su abandono del propósito inicial de su paseo, designio que por otra parte desconocemos, a fin de acompañar a Fedro parece ser, en principio, sumarse a la inquietud del Mirrino - esto es, interiorizarse con el discurso de Lisias - , pero su objetivo aparecerá mucho más complejo y sólo podrá ser determinado de modo cabal retrospectivamente al final.

Si nos detenemos en las referencias más puntuales al carácter átopos de Sócrates, de acuerdo con el comentario de Fedro en 230c-d, la atipicidad socrática se relacionaría con que éste se encontraría emplazado en un lugar que le es ajeno, a saber, el área fuera de la ciudad.

${ }^{27}$ Dice Sócrates a Fedro en 229a: "Tras desviarnos en este sitio, vayamos a lo largo del Iliso; después donde te parezca nos sentaremos con calma".

28 230c: "De modo que tu trabajo como guía ha sido excelente, mi querido Fedro". 
FEDRO: Pero tú, por cierto, sorprendente Sócrates, te muestras como alguien de lo más atípico (atopótatos).$^{29}$ Pues, te pareces sin más, como dices, a alguno que es guiado como un forastero y que no es de la región. Así ni te vas de la ciudad de viaje a tierras extranjeras, ni me das la impresión de que salgas para nada fuera de las murallas de la ciudad. ${ }^{30}$

Hay un juego aquí con el significado más literal de átopos: Sócrates está "desubicado", "fuera de lugar", porque le resulta desconocido todo otro sitio que no sea su ciudad natal. Pero, además, esta misma característica hace de él un individuo "raro", "atípico", pues, normalmente un habitante de Atenas conocería al menos las zonas aledañas.

Esta doble desubicación de Sócrates la vincula él mismo en su réplica a Fedro con su preocupación de aprender a través del diálogo con sus conciudadanos y su desinterés por el entorno no-humano, por el ambiente natural. Leemos así en 230d:

SóCRATES: Compréndeme, excelente amigo. Pues soy aficionado a aprender. ${ }^{31}$ Sin duda alguna los campos y los árboles nada me quieren enseñar, pero sí los hombres de la ciudad. Sin embargo, tú, me parece, has encontrado la pócima (phármakon) para que yo salga.

La atipicidad de Sócrates parecería entonces estar relacionada, según sus propias palabras, con la usual caracterización que de él hace Platón

${ }^{29}$ Vid. también 228b: "Bueno, no sería yo alguien singular (átopos) si, como los sabios, desconfiara; en ese caso, queriendo explicarlo racionalmente, diría que a ella el viento de Bóreas la arrojó de cabeza contra unas rocas cercanas, mientras jugaba con Farmacia y que, al haber muerto así, se dijo que fue raptada por Bóreas". Aquí Sócrates se coloca en una posición inusual respecto a la de los intelectuales de su época a quienes admira Fedro. Como dirá poco después en 230a, Sócrates no está interesado en estos juegos filosóficos, sino en conocerse a sí mismo.

${ }^{30}$ Por lo que sigue, lo atípico en Sócrates sería, aparentemente, salir del ámbito estrictamente humano e interesarse en la naturaleza. Como señala De Vries (1969, ad locum), Sócrates, si bien viajaba poco, en sentido estricto había salido de la ciudad, puesto que se lo representa a menudo yendo al Liceo o la Academia (Lis., 203a; Smp., 223d), al Pireo (R., 327a, 328b-c) - lugares todos situados fuera de las murallas - y había, además, participado en distintas campañas militares desarrolladas en otras regiones.

31 Sócrates se presenta como aprendiz en lugar de maestro. Esto se relaciona con que, frente al modelo tradicional del maestro, el tipo fundamental de sabiduría que le interesa impartir es la de la actividad misma de la indagación por la verdad más que algún tipo de doctrina. Vid. Ap., 33a. 
en los llamados diálogos tempranos o "socráticos", particularmente, por ejemplo, la Apología, a saber, como un hombre comprometido exclusivamente con los asuntos ético-políticos, e indiferente a las temáticas de la filosofía natural. ${ }^{32}$

Sin embargo, una consideración más atenta de la manera en que cada uno de los personajes se vincula con los mojones de la ruta que transitan, invita a una reconstrucción e interpretación más compleja con respecto al sentido de su situación topográfica y de la atipicidad socrática.

A pesar de que en varias oportunidades el texto sugiere que es Fedro quien guía la expedición en condición de conocedor de la zona (227c; 229a-b; 230b), las acotaciones de Sócrates a los comentarios de Fedro sobre el paisaje a medida que realizan su excursión campestre demuestran que él tiene en realidad mayor familiaridad que el propio Fedro con ese ámbito rural. Es Sócrates quien le sugiere ir a lo largo del Iliso para buscar un sitio apropiado para sentarse (229a); es él también quien conoce el lugar exacto donde habría tenido lugar el episodio de Oritia y, además, la existencia de los templos de Agra y de Bóreas en las inmediaciones $(229 \mathrm{c})$; maneja incluso la información respecto de una segunda alternativa topográfica del incidente de Oritia: ésta habría sido arrastrada por el viento Bóreas en realidad no desde los peñascos cercanos al Iliso sino desde el Areópago (229d).

La “des-ubicación” o carácter átopos de Sócrates que Fedro le reprocha no está vinculado entonces en realidad con los lugares que, como veíamos, Sócrates mejor que Fedro va situando y reconociendo a lo largo del camino por fuera de las murallas hasta el emplazamiento final. Aunque se muestra como ignorante, también en este plano Sócrates po-

${ }^{32}$ Las "antiguas acusaciones" de las que se defiende Sócrates en Ap., 19a-24b - y que entiende que están en la base de la actual acusación de corrupción de la juventud e introducción de nuevas divinidades - se vinculaban con asimilarlo con cosmólogos de la época como Anaxágoras por influencia sobre todo del retrato que hace de él Aristófanes en Nubes $(225-235 ; 250-253 ;$ 291-294; 317-318; 625-630). Otras fuentes antiguas también refieren a inquietudes de Sócrates por la filosofía natural como el mismo Platón en Phd., 96a-98b y Jenofonte en Mem., I, 1, 11-16; I, 6, 14; IV, 7, 2-7. El testimonio de Aristóteles en Met., 987b apoyaría la tesis de que el Sócrates histórico - que según se entiende habitualmente es el representado en obras tempranas como la Apología de Platón - sólo habría tenido intereses ético-políticos. De cualquier forma textos a favor de atribuirle un pensamiento cosmológico en realidad no contradicen que el centro de sus preocupaciones fueran los asuntos ético-políticos, sino que proyectan estos temas al ámbito del universo, tal como ocurre también en el Fedro. 
see un conocimiento del que Fedro carece. Es en realidad la manifestación asombrada de Sócrates en 230a-b respecto a la inusual belleza del sitio al que han llegado la que provoca el comentario crítico de Fedro en 230c respecto a su falta de inquietud de trasladarse más allá de las murallas de la ciudad. Leemos así en 230a-b:

SÓCRATES: A propósito, amigo mío, si puedo interrumpir un momento la conversación, ¿acaso este no era el árbol al que nos conducías?

FEDRO: Sin duda este mismo.

SÓCRATES: ¡Por Hera, ${ }^{33}$ bella por cierto la parada! Pues este plátano está muy expandido y alto, y la talla ${ }^{34}$ y la espesa sombra propia del sauzgatillo ${ }^{35}$ son absolutamente hermosas. Y como alcanza el pico máximo de floración, ¡cuán sumamente fragante es capaz de tornar al lugar! Y a su vez el manantial, de agua muy fría, al menos según da fe a mi pie, corre muy agradablemente bajo el plátano. Parece ser el santuario de algunas ninfas y de Aqueloo, ${ }^{36} \mathrm{a}$ juzgar por las estatuillas votivas de doncellas y en general por las imágenes sagradas ${ }^{37} \mathrm{Y}$, de nuevo, si me lo permites, ¡ ¡cuán amable y agradable es el aire del lugar! Responde en eco, estival y armonioso, al coro de las cigarras. ${ }^{38}$

33 Juramento que Platón muchas veces pone en boca de Sócrates acompañando expresiones de admiración (cf. Ap., 24a; Hi. Ma., 287a; 291e; Grg., 449d; Tht., 154d) y que era propio de las mujeres. Su relación con el mundo femenino puede aludir a que se ha dicho que el lugar es apropiado para que las jovencitas jueguen allí y las ninfas lo habiten; por ejemplo: la descripción de la isla idílica de la ninfa Calipso en $O d$., 5 , 63 y ss. Por otra parte, puede haber un juego con Héra, la diosa, y aér (cf. Crt., 404b) cuyo carácter fresco y agradable tiene también un lugar central en la descripción de este entorno bucólico. Cf. Rowe 1999, ad locum.

${ }^{34} \mathrm{La}$ altura de los árboles está en relación con el lenguaje elevado y poético usado en toda esta sección por Sócrates. Cf. Rowe, 1999, ad locum.

${ }^{35}$ El vitex agnus castus es como el plátano un árbol propio de las regiones mediterráneas. Se caracteriza justamente por su tupido follaje, sus fragantes flores violetas o blancas y su altura. En la antigüedad se le atribuían propiedades antiafrodisíacas y por ello algunos comentadores lo vinculan con el éros casto propio del filósofo del que se hablará en el segundo discurso de Sócrates. Cf. De Vries 1969, ad locum.

${ }^{36}$ Sobre las ninfas cf. supra n. 24. Aqueloo era el dios de los ríos por excelencia.

${ }^{37}$ Se trata en ambos casos de figuras ofrecidas a los dioses. Estos diversos altares acentúan la idea de que hay una cierta presencia divina en el lugar.

${ }^{38}$ Esto apunta al cuento de las cigarras que Platón introduce en $P h d r ., 259$ a y ss., al promediar el diálogo: las cigarras serán el modelo a seguir por él y Fedro puesto que representan la habilidad de cantar y dialogar simultáneamente bajo la inspiración de las Musas, en especial de las más antiguas - Calíope y Urania - , las cuales informan a los dioses sobre la dedicación de los hombres a la filosofía. 
Pero lo más espléndido de todo es lo de la hierba, porque ha crecido lo suficiente en suave declive para que [alguien], al reclinarse, ponga la cabeza muy cómodamente. De modo que tu trabajo como guía ha sido excelente, mi querido Fedro.

La respuesta de Fedro, quien se burla de estas manifestaciones de Sócrates y lo califica entonces de atopótatos, demuestra que él no ve nada particular en el paraje donde han ingresado y se emplazan. Es Sócrates quien se desorienta al descubrir en el sitio una belleza extraordinaria ${ }^{39}$ y describirlo como lo que, en términos literarios, pasaría a denominarse locus amoenus, a saber, un lugar de gran hermosura natural que proporciona, además, un sentimiento pleno de seguridad y bienestar (vid. Martínez, 2008). Y es a su vez el lector que se identifica con el recorrido imaginario de Sócrates quien experimenta junto con él la sensación de ingresar y visualizar un sitio de índole distinta a lo conocido y habitual. Dicho de otro modo, nos "des-ubicamos" junto con él, nos apartamos de la mirada corriente sobre nuestro entorno, y nos trasladamos e instalamos con sus palabras, como lo venimos haciendo gracias a la guía de la pluma platónica desde el inicio del diálogo, en este lugar de inusual belleza sensible en todos sus aspectos: la vegetación frondosa y en floración, los arroyuelos transparentes, la diafanidad del aire son hermosos para los ojos; el sonido del viento y de las aguas cantarinas del arroyo, el coro rítmico de las cigarras, placenteros para el oído; el perfume del sauzgatillo y del aire puro, deliciosos para el olfato; se siente, además, en la piel el calor del sol en contraste con el alivio reparador de la sombra de los árboles y en los pies con la frescura del agua. Al orientarnos hacia este lugar, el cual de tan bello nos da la sensación de ingreso a "otra realidad", nos volvemos, como Sócrates, átopoi.

2. De la tierra al cielo: la atopía del filósofo "enamorado" y el hyperouránios tópos

El tránsito de la ciudad al campo hasta el locus amoenus en el prólogo del Fedro anticipa dramáticamente las peripecias de las almas humanas

\footnotetext{
${ }^{39}$ Así interpreta también aquí Friedländer (1969, p. 220) la atopía que Fedro encuentra en Sócrates.
} 
para elevarse desde el ámbito mortal y terreno hacia las regiones celestes por donde marchan, arrastrados por las revoluciones, los dioses inmortales, con el anhelo de acceder junto con ellos al "lugar fuera del cielo" donde la Belleza resplandece junto con las restantes Formas (véase Esteban Santos 1992 y 1994). De este modo en el mito del carro con corceles alados la indicación topográfica "de adentro hacia afuera" de la introducción se transforma en un "de abajo hacia arriba".

Por una parte, se representan dos ámbitos espaciales bien diferenciados y localizables en la cosmovisión de la época y que anticipan claramente la distinción aristotélica entre el "mundo sublunar" y el "mundo supralunar": aquí abajo, la Tierra como región de lo mortal donde las cosas nacen y perecen; allí arriba, los cuerpos celestes, inmortales, simbolizados a través de la caravana de los carruajes divinos (246c, 246d, $248 \mathrm{a}-\mathrm{b}, 248 \mathrm{c}, 249 \mathrm{a}-\mathrm{b}) .^{40}$

Es cierto que los dioses retratados en el mito del carro alado tienen como una de sus funciones plantear un paradigma de unidad psico-física con respecto a la condición humana. En el caso de las almas divinas, a diferencia de las de los hombres, sus "caballos" o aspectos irracionales son siempre buenos y dóciles en la conducción por parte del "auriga", es decir, de la razón. Debido a esto, en sus almas las alas de éros se despliegan poderosas y las elevan regularmente hacia la verdad (véase Fierro 2010). En cuanto a sus cuerpos no son impedimento sino puro vehículo -óchema; hárma - de la actividad inteligente del alma. ${ }^{41} \mathrm{El}$ dios constituye así el modelo de un alma unificada, sin conflictos entre sus distintos aspectos, de máxima potencia erótica para dirigirse hacia lo verdadero, e inserta en un "cuerpo-vehículo" que facilita esta constitución psíquica, a la cual, con más o menos éxito, el alma humana, intenta asemejarse. Esta función emuladora de los dioses explica que estos sean representados en términos marcadamente antropomórficos y, de hecho,

\footnotetext{
40 Como se dice en 248a todas las almas no-divinas "anhelan la región superior" (glixómenai mèn hápasai tô̂ áno), si bien la mayoría son incapaces de alcanzarla, en 249d, el filósofo "desprecia las cosas de abajo" (tôn káto dè amelôn). Si bien la "región superior" propiamente dicha es la que está arriba de todo - esto es, "el lugar fuera del cielo"-, el espacio sideral que recorren los carros de los dioses y los de las almas no-divinas desencarnadas se encuentra claramente situado en el mito por encima de la Tierra y, por lo tanto, "arriba" con respecto a ésta.
}

${ }^{41}$ Vid. Fierro 2013. 
con las figuras de los dioses del panteón olímpico, ${ }^{42}$ si bien hay un replanteamiento de la caracterización propia de la religión tradicional.

Pero, además de constituir los dioses un paradigma que debe guiar la existencia humana (Poratti 2010, pp. 357-364; Eggers Lan 1995), si bien no es posible establecer una correspondencia punto a punto entre ellos y los movimientos de los cuerpos celestes (vid. Hackforth 1952, pp. 72-74) como los expuestos en el Timeo, muchos elementos sugieren que ellos son además una representación mítica de este orden cósmico. Se dice así que los vivientes inmortales, es decir los dioses, viajan y administran todo el universo (cf. 246e-247a, 247b, 247e), que describen recorridos u órbitas (diéxodoi) circulares perfectas, cumpliendo su movimiento propio de modo consumado y de acuerdo con el conocimiento pleno de un orden inteligente. Además, Zeus, como líder de todos y ordenador de todas las cosas (247e), parece aludir o bien al concepto de Alma del Mundo del Timeo, responsable de todos los movimientos del universo, o bien el alma que mueve el primer cielo o "cielo de las fijas", que arrastra en su revolución al resto de los movimientos planetarios (contra Eggers Lan 1995). Hestia alude, probablemente, a la posición fija de la Tierra con respecto a los movimientos astrales que suponían explicaciones de la época (vid. Cornford 1937, pp. 120-34).

Cielo y Tierra refieren, pues, a regiones claramente localizables. En cambio, el lugar a donde a veces se asoman regularmente las almas de los dioses "a duras penas" o "parcialmente" (mógis) las almas humanas en los períodos post mortem en que abandonan sus sómata mortales estaría arriba de todo, ${ }^{43}$ "fuera del cielo", más precisamente, en su dorso:

${ }^{42} \mathrm{El}$ ejército de los dioses estaría conformado por los doce dioses principales del panteón olímpico, aunque no se los nombre expresamente a todos ellos: Zeus, Hera, Ares, Hefesto, Artemis, Apolo, Atenea, Hermes, Afrodita, Hestia, Deméter y Poseidón.

${ }^{43}$ Una contraposición semejante a la de "abajo"/“arriba" puede verse también entre "aquî" (enthénde) y "allî" (ekeíse), por ejemplo en el pasaje 249e: "Pero no es fácil para toda alma acordarse de aquellas cosas a partir de las de aquí. Ni para cuantas en aquel tiempo vieron brevemente las cosas de allí, ni para las que, al haber caído aquí, tuvieran tan mala suerte que, por haberse abocado a lo injusto a causa de ciertas compañías, fueron capaces de olvidarse de las cosas sagradas que en ese entonces vieron". Véase también 249d y 250d, donde se hablá de la belleza de "aquí" en contraposición a la belleza pura de "allî", y 247c, donde se hace referencia a un "poeta de aquí", es decir un mortal. Asimismo, a este ordenamiento espacial le corresponde un contrapunto similar en el orden temporal a través de la oposición que se traza entre "ahora" (nûn) y "entonces" (tóte): mientras que "ahora" refiere a nuestra forma de existencia actual, en 
En efecto, las llamadas "inmortales" [i. e. las de los dioses], cuando llegan a la cumbre, al trasladarse al exterior, permanecen en el espinazo del cielo (éxo poreutheîsa éstesan epì toû ouranoû nótoi). Y, al posicionarse ellas así, la revolución las arrastra circularmente y éstas contemplan las cosas que están fuera del cielo (tà éxo toû oranoû, Phdr. 247c).

Y es aquí, en este lugar (tópos) supraceleste, donde se hallaría lo que verdaderamente existe, es decir, la Belleza resplandeciente junto a las restantes Formas, objeto del verdadero conocimiento:

\begin{abstract}
Al lugar supraceleste (tòn hyperouránion tópon) no ha habido hasta ahora poeta alguno de los de aquí que lo celebre como merece ni nunca lo habrá. Pero es así - ya que, ciertamente, uno debe atreverse a decir la verdad, sobre todo al referirse a la Verdad. ${ }^{44}$ Pues bien, esta región (tòn tópon) la ocupa la realidad incolora, informe e intangible, la cual genuinamente existe, es contemplada únicamente por el piloto del alma - el intelecto- y con la cual se vincula el género del conocimiento verdadero (Phdr. 247c-d) ${ }^{45}$
\end{abstract}

Ahora bien, a diferencia de la Tierra y la región celeste, de acuerdo con las teorías astronómicas de la época 46 "fuera del cielo", esto es, más allá de las estrella fijas no había nada. Esto significa que el texto refiere a un sitio inubicable desde el punto de vista de las coordenadas espaciales, es decir, de lo, de algún modo, localizable. ${ }^{47}$ Si el movimiento

la cual estamos hundidos en el olvido de las Formas (249b), "entonces" remite a una suerte de momento primordial en que teníamos un conocimiento completo (249e; 250c). Sobre las limitaciones del conocimiento humano vid infra n. 66.

44 Vuelve a indicarse aquí las limitaciones de todo discurso humano, en este caso para referirse a la naturaleza de las Formas (vid. 246a). No obstante, el filósofo-poeta, Platón, sería quien podría producir el discurso más verdadero al respecto.

45 Tal como se dice de la Belleza en sí en Banquete, la Forma trasciende cualquier manifestación particular, carece de las propiedades de lo sensible, como el color o el carácter tangible y, fundamentalmente, es lo que da lugar al conocimiento verdadero (vid. infra n. 50).

46 Para una síntesis de las distintas ideas astronómicas que circulaban en ese momento y de su posible correspondencia con lo que se representa a través del mito de los carros alados de los dioses del Fedro, vid. Hackforth 1952, pp. 72-74.

47 Tal como muestra este esquema, la alegoría del sol y de la caverna de República la distribución "arriba" las Formas, "abajo" las cosas sensibles no es nueva y con razón se la considera característica de la metafísica platónica; por otra parte, similarmente al tópos hyperouránios el Bien se encuentra epékeinas tês ousía (R., 509b). Pero en este 
de las almas en las revoluciones celestes representa a grandes rasgos, como vimos, el movimiento de los astros, no hay en realidad ningún lugar "por fuera" del universo al que las almas divinas y no-divinas puedan asomarse. Una interpretación plausible de esto podría ser que el mito representa en dos momentos, a fin de establecer una comparación entre el ámbito divino y el ámbito humano, algo que ocurre en realidad simultáneamente: los astros realizan los movimientos pertinentes según un orden racional que ya tienen perfectamente incorporado - conocido- en sus almas. En cambio, en el caso de las almas humanas, este conocimiento, que no es otro que el conocimiento de las Formas, es algo a recuperar, a "recordar" mediante la práctica de la filosofía. Las Formas no se encuentran en realidad en "otro mundo" en un sentido físico, sino que constituyen más bien "otra dimensión", el aspecto inteligible de la realidad en su conjunto que sólo a través de la razón y no de los sentidos podemos captar, tal como leemos en 249b-c:

Y en esto consiste la reminiscencia de aquellas cosas que nuestra alma una vez vio cuando, al viajar en compañía del dios y desdeñar las cosas que ahora decimos que son, asomó su cabeza hacia la verdadera realidad. Por ello es justo que únicamente el intelecto del filósofo adquiera alas. ${ }^{48}$ Pues, gracias a la memoria, [su pensamiento] está, en la medida de lo posible, siempre junto a aquellas cosas por cuya proximidad el dios es divino. ${ }^{49}$ Efectivamente, un

texto no están en juego referencias espaciales literales junto con las míticas, como es el caso del Fedro. En el caso del mito geográfico del final del Fedón el mundo sensoperceptible se encuentra en un agujero en la Tierra y el suprasensible por encima de la Tierra, lo cual tampoco puede tomarse literalmente, si bien puede verse detrás de él un simbolismo cosmológico (vid. Sedley 1999). En contraposición al hyperouránios tópos, la denominación de "llanura de la verdad" (tò aletheías pedíon, 248c) para referirse al plano eidético de la realidad si bien es también locativa es puramente metafórica.

${ }^{48}$ A través de la reminiscencia, es decir de la práctica activa de de comprensión de la estructura eidética de lo real, se desarrollan las "alas" de éros, es decir el amor por la verdad. La descripción de este proceso como un "recordar", si bien de un tipo especial, implica que es gradual y que podríamos no recuperar completamente aquello que intentamos rescatar del olvido.

49 Se continúa aquí con uno de los hilos conductores del mito, a saber, el deseo de asemejarnos al dios lo más posible en la medida en que recuperamos el conocimiento de las Formas y operamos de acuerdo con éste. Se especifica aquí que el método es el de la práctica de la reminiscencia - o, como se expresa en otras partes de la obra, de la verdadera dialéctica - y el punto de partida es la multiplicidad sensible. Por otra parte, es notorio que aquí se sugiere que los dioses son divinos por su eficiencia para estar en 
hombre, al utilizar correctamente estos recordatorios e iniciarse constantemente en los misterios perfectos/en misterios siempre perfectos, ${ }^{50}$ es el único que llega a ser verdaderamente perfecto. ${ }^{51}$

En consonancia con lo aquí expresado, quien no ha bloqueado completamente su recuerdo de esa "otra realidad" y se enamora o contempla cosas bellas no ve simplemente algo bello, sino que "recuerda" algo que no se puede ver con los ojos pero sí comprender como fundamento de todo lo que es bello: la Belleza. ${ }^{52}$ Es precisamente esta "des-ubicación" respecto al modo ordinario de comprender el mundo la que hace del filósofo, y también del verdadero amante y poeta - todos ellos considerados amantes de lo bello y ubicados en el primer puesto entre las formas de existencia encarnada (248d) - , un poseído por la manía erótica enviada por los dioses. Leemos en 249d-e:

He aquí, entonces, en qué deriva todo el argumento sobre la cuarta forma de locura. En lo que se refiere a ella, cuando alguien, al mirar la belleza de aquí y recordar la verdadera Belleza, adquiere alas y, con sus alas extendidas y un anhelo de elevarse sin poder hacerlo, mira hacia arriba como un pájaro y desprecia las cosas de abajo, tiene derecho a ser considerado loco. ${ }^{53}$ En con-

contacto con las Formas y no viceversa. Esto se vincula con la reformulación de Platón del concepto griego de lo divino.

${ }^{50}$ Aeí puede referirse al acto de iniciarse y/o a los misterios. El primer caso implicaría que el filósofo en un momento dado puede adquirir la capacidad de establecer continuamente contacto con la verdadera realidad. En el segundo caso, los misterios, entendidos como práctica de la filosofía, siempre serían perfectos.

${ }^{51}$ Hay aquí un juego de palabras en griego irreproducible en castellano: teleîsthai es "realizarse, consumarse, cumplirse" y, en ese sentido, "perfeccionarse", y también "ser iniciado en los misterios". El grado de perfección o areté en la condición humana depende de cuán capaces somos de rememorar la visión de las Formas, y esto constituye, a su vez, la forma más perfecta de iniciación.

${ }^{52}$ Mientras que en el Fedro se destaca el resplandor y condición palmaria de la Belleza (lamprón, 250b; en augề katharầ, 250c) y sus manifestaciones sensibles, es en el Banquete donde encontramos una caracterización de la Forma de la Belleza (captable sólo por el pensamiento): es pura — es decir que posee como su única propiedad el ser bella sin estar mezclada con otras propiedades, tal como ocurre en las cosas concretas - ; absoluta - esto es no relativa al momento, el lugar o a quien realiza el juicio de belleza-; inmutable e idéntica a sí misma, divina, y de la cual las cosas bellas participan sin que ella crezca o disminuya (Smp., 211a-b).

${ }^{53}$ En nuestra forma de existencia actual el éros del filósofo tiene "alas", pero no son tan fuertes para elevarse hasta la verdad, es decir para alcanzar un conocimiento pleno y 
secuencia, ésta deviene, para el que la adquiere y se asocia a ella, la mejor de todas las formas de inspiración divina y con origen en los mejores elementos. Y, a causa de participar de esta locura, el amante es llamado amante de las cosas bellas. ${ }^{54}$

No obstante, como esta rememoración o anámnesis no puede ser en el caso de la almas humanas completa, al menos en nuestra forma de existencia actual, este desajuste que se produce respecto a la comprensión de nuestro entorno cuando nuestra existencia se direcciona a este "no lugar" nos coloca en una incomodidad permanente, tal como se evidencia claramente en el caso del verdadero enamorado, quien experimenta en cuerpo y alma una situación inusual o atopía:

A raíz de ambos sentimientos mezclados se angustia por lo atípico de su afección y, al sentirse perplejo (tèn atopían toû páthous kaì aporoûsa lyttâi), se enfurece y, por estar enloquecida, ni es capaz de dormir durante la noche ni de permanecer donde está durante el día, y corre llena de anhelo hacia donde cree poder ver al poseedor de la belleza; y, al verlo y canalizar ${ }^{55}$ su ansia, libera las cosas contenidas en el pasado, y al tomar un respiro, cesan los aguijonazos y los dolores de parto, ${ }^{56} \mathrm{y}$ disfruta además en ese momento de este dulcísimo placer (Phdr., 251e).

La atopía - "carácter atípico, extraño" - de la experiencia de enamorarse, en la medida que hace recordar al alma su anhelo por la Belleza en sí, la deja en un estado del que no sabe cómo salir -aporoûsa-, en forma similar a lo que intenta hacer Sócrates en los llamados diálogos "tempranos" o "aporéticos" a través de la refutación de sus interlocuto-

estable de las Formas. Su condición es equiparable a la del éros metaxý — "intermediointermediario" - del Banquete, que se ubica en un punto intermedio entre lo divino y lo mortal.

54 Vid. también 251 a-b: "En cambio, el recién iniciado, quien contempló multiplicidad de cosas en aquel entonces, cada vez que ve un rostro de aspecto divino o una figura corporal semejantes a los de los dioses que imitan bien la Belleza, al principio se estremece y algo de sus antiguas conmociones lo asalta. Después, al mirar [al amado], lo venera como a un dios y, si no temiera la reputación de desmedida locura, le haría ofrendas al jovencito como a un ídolo y un dios. Y, al verlo, como es natural a raíz del estremecimiento, un cambio se apodera de él, un sudor y temperatura desacostumbrados".

55 Sobre el uso de epoxeteusaméne vid. Dodds 1959, Grg., 493e.

${ }^{56}$ Cf. Smp., 206a y R., 490b. 
res. Esta condición inquietante es, no obstante, en ambos casos propicia para promover el surgimiento del éros filosófico. Contrariamente a la posición del sentido común retratada en los dos primeros discursos del Fedro, la perturbación existencial que conlleva el surgimiento de éros es aquí considerada algo positivo en tanto que produce una crisis en nuestra visión habitual del mundo y nos abre la puerta a una comprensión distinta de nosotros mismos y de la realidad (vid. Fierro 2006, 2012). Así, uno de los mensajes del Fedro es que el desplazamiento hacia un "no-lugar" o estado de atopía constituye uno de los requisitos para que sea posible tanto el amor verdadero como la vida filosófica.

\section{Entre la dóxa mortal y la epistéme divina: los lógoi "atípicos”} de la filosofía

Finalmente reflexionaremos sobre la relación que se establece en el diálogo entre el tipo de emplazamiento de cada uno de los personajes y el tipo de conocimiento y discurso que le corresponde.

A Fedro se lo describe, y seguramente era conocido en su medio, como un entusiasta no nada más consumidor (227a, 228a-c, 234d, 238c, 243b, 257c, 258e), sino promotor de discursos (238e; 242a-b; 242e; 243e). En el caso del prólogo, se nos dice que proviene claramente de la casa de Epícrates, un conocido sofista de la época, en la que en la actualidad se ofrecen "festines" de discursos y donde Lisias, uno de los "logógrafos" más famosos del momento, ha realizado esa mañana una epídeixis o demostración (227a). Su lugar natural de pertenencia es por lo tanto la pólis de Atenas y las prácticas discursivas que ésta suponía. A esto se agrega su desplazamiento fuera de las murallas pero con un fin predeterminado para su paseo - vigorizar su cuerpo y aprenderse de memoria el discurso escrito de Lisias - y, en principio, con un conocimiento acabado de los alrededores. Su intención es dedicarse a repetir y memorizar mecánicamente, sin reflexión, el discurso de Lisias. ${ }^{57}$ Cons-

${ }^{57}$ Como observa Velardi (2006, pp. 19-24), a través de lo que Fedro se plantea hacer con el discurso de Lisias se representa la práctica mnemotécnica que solían proponer los maestros de retórica de la época, particularmente los logógrafos: incentivar la repetición palabra por palabra de memoria de un discurso dado, sin apuntar al desarrollo de la capacidad de reflexión o recreación. Como muestra la historia de Teuth y Thamus (274) el valor de la mnéme - y mucho más de la anámnesis de las Formas (vid. Scott 1987, 
tituye entonces un epítome de los "intelectuales" o sophoí de la época y le corresponde el lógos sofístico tal como suele caracterizárselo en el texto platónico: un discurso persuasivo y, por ende, exitoso para los fines individuales y/o políticos, pero neutral y acrítico respecto a su contenido e, incluso, respecto a la disposición de sus elementos. ${ }^{58}$

Fedro representa un ejemplo de la mayoría de las almas no-divinas que no acceden al tópos hyperouránios donde se halla verdadero conocimiento y quedan sumergidas en la región inferior de la opinión (dóxa):

El resto de las almas van detrás, todas anhelando la región superior pero siendo incapaces [de alcanzarla]. E inmersas [en la región inferior], son transportadas conjuntamente en círculos, pateándose y atropellándose, cada una intentando aventajar a la otra. Así pues, hay confusión, rivalidad y sudor extremos ${ }^{59}$ A partir de esta situación y debido a la maldad (kakía ${ }^{60}$ de los aurigas muchas se mutilan y muchas otras se quiebran gran número de alas. ${ }^{61}$ Y todas estas, tras el gran esfuerzo realizado, se apartan de la contemplación de lo que es sin iniciarse en ello. ${ }^{62} \mathrm{Y}$, después de marcharse, se sirven de la opinión como alimento (tropheî doxastê̂ chrôntai, Phdr., 248a-b)

quien destaca el esfuerzo y actitud activa que requiere la anámnesis platónica frente al apriorismo kantiano) - reside para Platón no en la reproducción mecánica sino en la comprensión del sentido.

58 Así se afirma en 260a: “Asimismo he oído respecto de esto, querido Sócrates, que no es necesario para el que va a ser orador aprender las cosas que realmente son justas, sino las que lo parecen a juicio de la mayoría; ni tampoco las que son realmente buenas y bellas, sino cuantas parezcan ser así. Pues la persuasión se da a partir de estas cosas y no a partir de la verdad". En cuanto a la falta de atención en lo referente a la "disposición" (diáthesis), más allá de las insuficiencias en el contenido, cf. 236a.

${ }^{59}$ Entre aquellos que se mantienen en el nivel de la dóxa hay rivalidad, a diferencia de lo que ocurre al nivel de los dioses o quienes se le asemejan, quienes actúan de acuerdo con el conocimiento o epistéme y únicamente se preocupan por la ejecución de su propio itinerario.

${ }^{60}$ La "maldad" (kakía) es consecuencia de la ignorancia por no llegar a contemplar la llanura de la verdad. Por eso, puede traducirse por "incompetencia" o "incapacidad".

${ }^{61}$ La impericia de los cocheros consiste en su incapacidad para conocer y ejecutar lo bueno: la inadecuada organización de su estructura psíquica impide que la razón opere correctamente y pueda dirigirse hacia lo auténticamente bueno y, entonces, las "alas" de su éros por la verdad se quiebran. Vid Fierro 2010.

${ }^{62}$ Los ritos iniciáticos de las religiones mistéricas, particularmente de los Misterios de Eleusis, son reinterpretados en clave platónica como iniciación filosófica, esto es, ser iniciado significa contemplar en algún grado las Formas, ya sea en nuestra vida actual o después de la muerte. 
Esto no impide, no obstante, que Fedro pueda ser desviado por Sócrates de ese lugar de no cuestionamiento donde tenía planeado instalarse (después de todo, como leemos en el pasaje recién citado, "todas" las alma anhelan la región superior), y ser atraído hacia otra "zona" que promueva la reflexión filósofica. ${ }^{63}$

En el caso de Sócrates, si bien también se lo presenta como a Fedro como un "fanático" o "enfermo" por los discursos (227c, 228b, 230de, 236e), a diferencia de éste, declara que su única preocupación es el "autoconocimiento" al tiempo que rechaza la producción de racionalizaciones o lógoi superficiales de los intelectuales del momento (230a). Por otra parte, así como parece no tener un itinerario predeterminado sino que más bien lo traza ad hoc a fin de realizar un camino compartido con su interlocutor de turno, Fedro, ${ }^{64}$ del mismo modo, si bien en primera instancia parecería estar tan interesado como Fedro en el discurso de Lisias, se "desvía" de esta aceptación incondicional del Mirrino y presenta, en contrapunto, cuestionamientos a su forma y contenido. Esto lo hace, además, a través de nuevos discursos que no sólo objetan el de Lisias, sino que derivan en un ahondamiento tanto de las temáticas inmediatamente presentadas por Lisias/Fedro como de cuestiones concernientes a otras esferas, incluidas las más elevadas. ${ }^{65}$ A esto le suma posteriormen-

${ }^{63}$ El juego de seducción entre Fedro y Sócrates, que se mantiene a lo largo de todo el diálogo, es inseparable de la seducción que ejercen sobre ambos los discursos y, en el caso de Sócrates, de su objetivo de atraer a Fedro hacia la filosofía. No hay, pues, dos temas - éros y retórica - distribuidos en dos partes del diálogo, sino que ambos temas se encuentran en realidad entrelazados a lo largo del Fedro. Respecto al problema de la unidad temática y estructural del Fedro puede verse, entre otros, Rowe 1986.

${ }^{64}$ Como ya señalamos, si bien Sócrates se presenta a primera vista como desconocedor del área rural, hay detalles que revelan que esto es más bien una fingida ignorancia. Sin embargo, no es insincera su actitud de "hacer camino al andar" ni en lo literal ni en lo simbólico: no había planeado de antemano ese recorrido con Fedro, aunque conozca, tras el encuentro, bien el lugar a donde quiere llevarlo; tampoco llevaba preparada la conversación a sostener con él, aunque tenga claro a qué tipo de reflexiones querría conducir a Fedro. Por supuesto, todo esto es válido sólo en el plano ficcional, pues Platón, el escritor, controla, cual demiurgo, de principio a fin su obra y sus personajes.

${ }^{65}$ Así como en el prólogo, si bien afirma Sócrates que sólo le interesan los hombres, se muestra luego capaz de apreciar la naturaleza y percibir la belleza que ésta irradia, del mismo modo en su segundo discurso se puede desplazar de cuestiones más acotadas y puramente humanas que han sido tratadas en el discurso de Fedro/Lisias y su primer discurso - básicamente los perjuicios o bondades de éros en la relación amorosa erastés-erómenos; las cualidades de los buenos y malos discursos - a temáticas de 
te, una reflexión dialogada con Fedro en que se examina ya de modo más amplio las condiciones del bien pensar y decir en general (cf. 260d; 272a; 273d; vid. Dixsaut, 2011). De este modo el paseo intelectual de Sócrates, al que se suma Fedro, en la medida en que haya podido seguir el intrincado trayecto, se extiende del plano humano, tanto individual como político, al plano cósmico e incluso "más allá", de modo que termina considerablemente lejos del punto de partida de Fedro (el discurso lisíaco que se proponía aprender de memoria). Pero, pese a este contundente avance respecto a los diversos temas abordados así como del entrelazamiento entre ellos, hay indicaciones de que los resultados son provisionales en tanto pueden reformularse ya de modo más acabado, ya simplemente desde otro ángulo de análisis. En este sentido el Fedro constituye un ejemplo de imitación acabada que puede lograr un discurso escrito de una conversación dialéctica "en vivo", es decir del discurso "atípico" de un filósofo.

Esta situación del lógos desarrollado por Sócrates encaja con la de las almas filosóficas del mito del carro alado, las cuales quedan a medio camino entre el resto de almas no-divinas y las almas divinas: logran espiar en la región superior pero "apenas" y "parcialmente" (mógis) para volver luego a hundirse en la región de la dóxa:

[...] En el caso de las demás almas, la que mejor sigue al dios y se le ha asemejado más, saca la cabeza hacia el lugar fuera del cielo (tòn éxo tópon) y es trasladada en círculos con la revolución, aunque, aturdida por los caballos, ${ }^{66}$ apenas $^{67}$ avistan las cosas que son. Mientras que otra alma a veces se eleva,

mayor alcance como la consideración de la existencia humana en su entramado con el movimiento incesante de la vida en el universo, y la organización de todo el devenir de acuerdo la estructura eidética representada en el hyperouránios tópos.

${ }^{66}$ En el caso de las almas humanas y de las almas no-divinas en general, los caballos, que siempre representan lo irracional y, al mismo tiempo, la fuerza de propulsión del alma, son de naturaleza contraria, puesto que el caballo negro simboliza el deseo del alma por lo mortal y terrenal, cuya dirección es opuesta a la del éros alado por la verdad, y desequilibra con ello al resto del alma, esto es al auriga y al caballo blanco, los cuales no pueden servirse del carro como vehículo para dirigirse a la auténtica realidad.

${ }^{67}$ Mógis - "apenas" - indica que la visión de este grupo de almas de lo que realmente es "parcial" y/o "esforzada". En cualquier caso, tanto en nuestra forma de existencia actual como en una eventual existencia ante nativitatem y post mortem, es uno de los indicadores en los textos de Platón, junto con exaíphnes - "instantáneamente"-, término que refiere a los condicionamientos de temporalidad para el acceso a una reali- 
a veces se hunde $\mathrm{y}$, al ejercer su fuerza los caballos, ven algunas cosas pero otras no (Phdr., 248a).

Similarmente se afirma que, en nuestra forma de existencia actual, si bien estas almas son las únicas capaces de recordar las Formas, lo hacen con dificultad por haber sido restringida su visión: ${ }^{68}$

Así pues, tal como se dijo, toda alma humana por naturaleza ha contemplado la realidad. De lo contrario no hubiera ingresado en esta forma viviente. ${ }^{69}$ Pero no es fácil para toda alma acordarse de aquellas cosas a partir de las de aquí. Ni para cuantas en aquel tiempo vieron brevemente las cosas de allí, ni para las que, al haber caído aquí, tuvieran tan mala suerte que, por haberse abocado a lo injusto a causa de ciertas compañías, fueron capaces de olvidarse de las cosas sagradas que en ese entonces vieron $(P h d r ., 250 a) .^{70}$

Es por ello que el acceso pleno al sentido último de la realidad queda reservado sólo para los dioses,${ }^{71}$ mientras que incluso al filósofo se le

dad eterna, de las limitaciones del conocimiento humano de las Formas, a diferencia del conocimiento divino. Vid. Steinhal 1993.

${ }^{68}$ La situación ante nativitatem y post mortem de las almas no divinas es paralela a la de su existencia encarnada. Se compara así la situación de conflicto con el caballo negro de los carros de las almas no divinas (247b; 248a) con el conflicto del alma del enamorado cuando ve al bello amado (253d-254e).

${ }^{69}$ Se reitera aquí que sólo las almas de los humanos han contemplado, al menos en parte, las Formas, pues son los únicos organismos vivientes mortales capaces de operar con conceptos universales.

${ }^{70}$ La anámnesis de las Formas es un trabajo que requiere según el individuo mayor o menor esfuerzo no sólo porque el contacto con la verdadera realidad presenta distintos grados de dificultad y parcialidad - mógis (vid. supra n. 66) - , sino también porque de acuerdo con la duración de la visión varía el grado de perdurabilidad de la impresión que deja en el alma. El que todos estos factores intervengan previamente a la encarnación del alma en un cuerpo mortal con una forma de vida determinada expresa de algún modo que la capacidad de rememoración de las Formas es distinta en cada uno. No obstante, también vuelve a subrayarse, aquí en el plano de nuestra forma de vida actual, el peso de la responsabilidad humana, puesto que la injusticia o justicia con que cada persona se entrega a esa existencia dada también obstaculiza o agiliza la posibilidad de que el alma escape del olvido de su propia naturaleza y al mismo tiempo de la verdad.

${ }^{71}$ Leemos así en 247d-e: "Pues bien, esta región la ocupa la realidad incolora, informe e intangible, la cual realmente es, es contemplada únicamente por el piloto del alma - el intelecto - y con la cual se vincula el género del conocimiento verdadero. La mente del dios, por nutrirse del intelecto y del conocimiento sin mezcla y ser propio de 
niega el poder de referirse acabadamente al tópos hyperouránios, lo cual implicaría poder dar un cierre definitivo a su discurso, si bien se valida, al mismo tiempo, su intento de aproximarse a este objetivo:

Al lugar supraceleste no ha habido hasta ahora poeta alguno de los de aquí que lo celebre como merece ni nunca lo habrá. Pero es así - ya que, ciertamente, uno debe atreverse a decir la verdad, sobre todo al referirse a la verdad (Phdr., 247c, mis itálicas). ${ }^{72}$

El filósofo entonces que recrea el Fedro de Platón no es átopos porque se mueva de la seguridad del discurso establecido hacia la creación de un discurso propio desde el universo simbólico dado, sino fundamentalmente porque, aún en este caso, queda instalado en un amparo precario y transitorio, puesto que su pensamiento y sus palabras, y más aún su existencia en su conjunto, no hallan descanso definitivo en la "llanura de la verdad". ${ }^{73}$ Su constitución en el "amor a la sabiduría" lo obliga, pues, a un eterno peregrinaje en la búsqueda de una explicación acabada del sentido total de la existencia humana y cósmica (cf. también el final de $R ., 10,621 \mathrm{c})$. Este "largo camino" (274a) de autocomprensión, donde el punto de llegada se transforma continuamente en nuevo comienzo y es preciso permanentemente "desacomodarse", conformaría, pues, la situación característica en que nos ubica, o mejor dicho nos "des-ubica", la elección del modo de vida filosófico.

toda alma que está dispuesta a recibir lo apropiado, se complace al ver lo real después de mucho tiempo, y se nutre y se siente feliz al contemplar las cosas verdaderas, hasta que la revolución conduzca [al alma] en círculos hacia este mismo lugar. Durante la revolución [la mente divina] avista la justicia en sí, avista la temperancia, avista el conocimiento: no aquél que está sujeto al devenir, ni el que de cierta manera se diversifica al darse en cosas diversas, a las cuales nosotros llamamos en nuestra existencia actual «realidades», sino el real conocimiento que se da en lo que realmente es".

72 Vuelve a indicarse aquí las limitaciones de todo discurso humano, en este caso para referirse a la naturaleza de las Formas. No obstante, el filósofo-poeta, Platón, podría producir un discurso más verdadero al respecto.

${ }^{73} \mathrm{Si}$, mutatis mutandis se aplicara aquí la intepretación que Palumbo (2012), con base en conceptos lacanianos, hace del Banquete, podría decirse que el Fedro se articula también en un último término en una "estructura de reenvío", pero no de un significante a un significado, sino de un significante a otro significante, representando así la estructura misma de la lengua, a la cual el establecimiento de un significado último le está vedado. 


\section{BIBLIOGRAFÍA}

Augé, M., Los “no-lugares”. Espacios del anonimato. Una antropología de la sobre modernidad, trad. M. N. Mizraji, Barcelona, Gedisa, 1996.

Chantraine, P., Dictionnaire étymologique de la langue Grecque, París, Klincksieck, 1968.

Cornford, F. M., Plato's Cosmology. The Timaeus of Plato, Cambridge, Heffer \& Sons, 1909.

De Vries, G. J., A Commentary on the Phaedrus of Plato, Amsterdam, Adolf M. Hakkert Publisher, 1969.

Dixsaut, M., Metamorphoses de la dialectique dans le dialogues de Platon, París, Vrin, 2011.

Dusanic, S., “Athenian Politics in Plato’s Phaedrus", Aevum, 66, 1, 1992, pp. 23-39.

EGgers LAN, C. E., “Zeus e anima del mondo nel Fedro", en L. Rossetti (ed.), Understanding the Phaedrus, Sank Agustin, Akademia Verlag, 1992, pp. 40-46.

Esteban SAnTos, A., "Interior/exterior: antítesis en la temática y en la estructura del Fedro", Cuadernos de Filología Clásica, 2, 1992, pp. 165-185.

—, "Diálogo en la yerba: funciones de la introducción y el escenario del Fedro", en J. M. Maestre, L. Charlo Brea \& J. Pascual Barea (eds.), Humanismo y pervivencia del mundo clásico: homenaje al profesor L. Gil, Cádiz, Ayuntamiento de Alcañiz-Universidad de Cádiz, 1994, pp. 289-304.

Ferrari, G., Listening to the Cicadas, Cambridge, Cambridge University Press, 1990.

FiErro, M. A., "Platón y los privilegios de los amantes", Nova Tellus, 24. 2, 2006, pp. 170-195.

- , "El concepto filosófico de metaxý en el Banquete de Platón”, en J. Martínez Contreras (ed.), El saber filosófico, México, Siglo XXI-AFM, 2007, pp. 249-254.

- , "La concepción del éros universal en Fedro", en J. Labastida y V. Aréchiga (eds.), Identidad y diferencia, vol. 2, México, Siglo XXI-AFM, 2010, pp. 11-25.

- , "La philosophía según Platón”, en O. Nudler, M. A. Fierro y G. Satne (eds.), La filosofía a través del espejo. Estudios metafilosóficos, Buenos Aires, Miño y Dávila, 2012, pp. 85-114.

- , "Two conceptions of the body in the Phaedrus", en G. Boys-Stones, C. Gill y D. El Murr (eds.), The Platonic Art of Philosophy, Cambridge, Cambridge University Press, 2013, pp. 27-50.

Friedländer, P., Plato 3. The Dialogues: second and third periods, trad. de H. Meyerhoff, Londres, Routledge \& Keagan, 1969.

LSJ= Liddell, H., G., R. ScotT, H. S. Jones, A Greek English Lexicon Oxford, Oxford University Press, 1940 (9 $9^{\text {th }}$ ed.).

Martínez, M., "Descripciones de jardines y paisajes en la literatura griega antigua", Cuadernos de Filología Clásica. Estudios griegos e indoeuropeos, 18, 2008, pp. 279-318. 
Michels, V. (Hg.), Materialien zu Hermann Hesses Demian, Erster Band, Frankfurt, Suhrkamp, 1993.

NudLER, O., "La filosofía socrática o una filosofía desde un no-lugar", en O. Nudler, M. A. Fierro, y G. Satne (eds.), La filosofía a través del espejo. Estudios metafilosóficos, Buenos Aires, Miño \& Dávila, 2012, pp. 19-51.

Palumbo, L., "Eros e linguaggio nel Simposio", en A. Borges de Araújo \& G. Cornelli, Il Symposio di Platone: un bachetto di interpretazioni, Nápoles, Loffredo, 2012, pp. 139-158.

PHILIP, A., "Récurrences thématiques et topologie dans le Phèdre de Platon", Revue du Metaphysique et de Morale, 86, 4, 1981, pp. 452-476.

Platon, Opera, 5 vols., recognovit brevique adnotatione critica instruxit I. Burnet, Oxford, Oxford University Press (Oxford Classical Texts), 1900-1907.

—, Fedro, trad., introd. y nts A. Poratti, Madrid, Akal, 2010.

—, Fedro, ed., introd. y com. R. Velardi, Milán, Bur Rizzoli (Classici Greci e Latini), 2006.

—, Gorgias, ed., introd. y com. E. R. Dodds, Oxford, Clarendon Pres, 1959.

-, Phaedrus, trad., introd. y com. R. Hackforth, Cambridge, The Bobbs-Merrill Company, 1952.

-, Phaedrus, trad., introd. y com. C. J. Rowe, Warminster, Aris \& Phillips, 1999 ( $2^{\mathrm{a}}$ ed.).

-, Phaedrus, ed., introd. y com. H. Yunis, Cambridge, Cambridge University Press, 2011.

—, Phédon, introd. L. Robin, ed. y trad. P. Vicaire, París, Les Belles Lettres, 1951.

—, Phèdre, trad., introd. y nts. L. Brisson, París, Flammarion, 1989.

-, Phèdre, introd. L. Robin, ed. de Cl. Moreschini, trad. de P. Vicaire, París, Les Belles Lettres, 1954.

—, Symposium, ed., nts. y com. R. G. Bury, Cambridge, Heffer \& Sons, 1909.

RYAn, P., Plato's Phaedrus: A Commentary for Greek Readers, Norman, University of Oklahoma Press, 2012.

Rowe, C. J., "The Argument and Structure of Plato's Phaedrus", Proceedings of the Cambridge Philological Society, 32, 1986, pp. 106-25.

SCHENKER, D., "The Strangeness of the Phaedrus", The American Journal of Philology, 127, 1, 2006, pp. 67-87.

ScotT, D., "Platonic Anamnesis Revisited", Classical Quaterly, 37, 2, 1987, pp. 346-366.

SEDley, D., "Theology and myth in the Phaedo", Proceedings of the Boston Area Colloquium in Ancient Philosophy 5, 1989, pp. 359-383.

Steinthal, H., "Mógis und exaíphnes: Platon über die Grenzen des Erkennens", en C. Neumeister (ed.), Antike Texte in Forschung und Schule. Festschrift für W. Heilman zum 65. Geburstag, Frankfurt am Main, Diesterweg, 1993, pp. 99-105. 
Travlos, J., Pictorial Dictionary of Ancient Athens, Londres, Thomas \& Hudson, 1971.

Wyncherley, R. E., "The Scene of Plato's Phaedrus", Phoenix, 17(2), 88-98, 1963. 
